\title{
Effect of using mastery learning method on the performance level of some handball offensive skills for Umm Al-Qura University students \\ ${ }^{1}$ Dr. Khaled Hussein Mohamed aly \\ Introduction
}

The modern era is Characterized an accelerated knowledge explosion, which makes the need to improve the quality of education an important necessity for societies, so that the learner is prepared to reach acceptable levels of performance to suit the needs of society and requirements of modern times (6:158)

The mastery learning strategy is one of the educational strategies that aims at providing students with successful learning experiences may not provide them with traditional teaching methods. The main principle of the learning method is to master that most students can reach their maximum learning ability if the teaching style is organizing. (10:65)

According to Ismail Sadiq (2001) mastery learning is based on the fact that the learning objectives are specific and must be prepared by the teacher in advance with the provision of educational alternatives to learners in addition to the educational content continuum. (8:257)

The skills of motor are the basis of any sport game, where the proficiency of the player to these skills to rise in the level of technical and aesthetic of the game ، Handball, as a collective sport, has become an advanced center for all sports. It is characterized by a multiplicity of technical skills that a player must acquire in order to be able to perform the duties required of him during matches (11:33) $(12: 19)$

The researcher believes that learning and mastering offensive skills in handball requires a lot of time and effort to master these skills, so that the learner can use these skills efficiently in various motor situation

\footnotetext{
${ }^{1}$ Lecturer in Team sports Games Department, Faculty of physical Education for men, Helwan University
} 
Through the experience of the academic researcher and the process of teaching handball course at the Department of Physical Education at Umm Al-Quri University in Saudi Arabia, he noted the low level of skill performance of students from the required level (expected), where the researcher believes that this drop in the level may be because of the learning method used and Often depends on the traditional method, in which the teacher makes all decisions about the learning process

Through the researcher's knowledge of many scientific references, it was found that choosing the best method to learn any skill is the one that achieves the required results and ensures the transfer of the positive learning effect between the skills to be learned, which is appropriate to the age level of the students and the difficulty of the skill to be learned. As a learning method may have a positive impact in learning the offensive skills in handball, and also takes into account individual differences among students and helps them to collect and practice and thus raise the level of their skill, which prompted the researcher to conduct the current study

Aim

The research aims to design and implement an educational program by using "mastery learning" method to identify its effect on the performance level of some offensive skills in handball for Umm Al-Qura University students.

\section{Research hypotheses:}

- There are significance statistical differences between the mean scores of the pre-and post-measurements for the experimental group in the performance level of some offensive skills in the handball in favor of the post measurement.

- There are significance statistical differences between the mean scores of the pre-and post-measurements for the control group in the performance level of some offensive skills in the handball in favor of the post measurement.

- There are significance statistical differences between the mean scores of the two posts of the experimental and 
control group in the performance level of some offensive skills in the handball in favor of the experimental group.

\section{Terminology}

The main term used in this study is "mastery learning". Mastery learning is A range of educational ideas and practices, and a set of teaching and evaluation procedures, aimed at improving the education provided to students so that they all or most of them reach the level of mastery of the educational material (1:159)

\section{Methods}

\section{Design:}

An experimental design was used in this study where two groups were manipulated

Table (1)

(a control versus an experimental group).

\section{Sample}

The sample assigned was a group of first level students of physical education department in Umm Al Qura University $\quad(n=60)$ The students were assigned into two groups: a control $(\mathrm{n}=30)$ and an experimental $(\mathrm{n}=30)$. In addition, participants/players were also assigned to two groups: distinguished $\quad(n=10$ professional players from El Wehda Team) and undistinguished $\quad(n=10$ first level students). The distinguished and undistinguished groups were used as benchmarks. The following table shows the sample of the study.

Description of the Sample $N=30$

\begin{tabular}{|c|c|c|c|c|c|c|}
\hline \multicolumn{2}{|c|}{ Variables } & $\begin{array}{c}\text { Measurement } \\
\text { Unit }\end{array}$ & Main & Median & SD & Skewness \\
\hline \multirow{3}{*}{ تُ } & age & year & 20.54 & 20.00 & 1.117 & 0.198 \\
\hline & height & $\mathrm{cm}$ & 170.21 & 170.50 & 4.208 & $0.162-$ \\
\hline & weight & $\mathrm{kg}$ & 69.10 & 69.50 & 3.502 & 0.177 \\
\hline 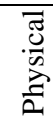 & Leg power & $\mathrm{m}$ & 1.91 & 1.90 & 0.312 & $0.042-$ \\
\hline
\end{tabular}

Follow Table (1)

Assiut Journal For Sport Science Arts 
Description of the Sample N =30

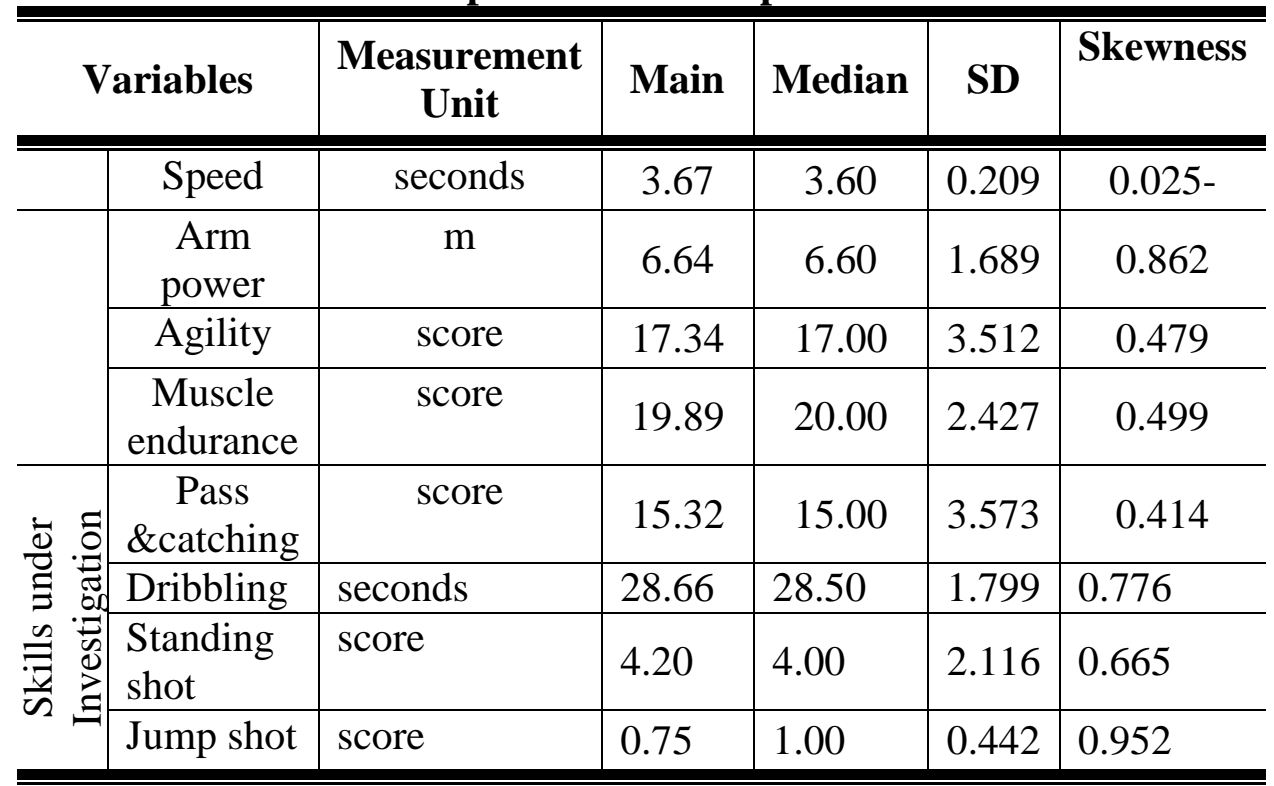

- Instrumentation

- Related studies

Related studies were reviewed to collect related information.

\section{- Equipment}

$\begin{array}{ll}\text { - } & \text { Rest-meter } \\ \text { - } & \text { A wall } \\ \text { - } & \text { CDmputers } \\ \text { - } & \text { mattress } \\ \text { - } & \text { Tape measure }\end{array}$

\section{- Checklists}

Some checklists were developed to collect data

\section{- Interviews}

Some interviews were conducted with a handball expert.

- Tests

four tests were administered to the sample of
- $\quad$ A handball court

- Scaled box

- $\quad$ stopwatch

- $\quad 30$ ball size (3)

the study. They included the passing \&catching test, the dribbling test, the standing shot and jump shot test Pilot Study. A pilot study of the instruments was conducted as part of the validation process of the study. The 10 participants of the 
undistinguished group were recruited in this phase.

- Validation

The tests were administered to the distinguished and undistinguished samples and the validity of the tests was achieved. Test reliability was achieved by using a test-retest method. The reliability coefficients of the tests used were 0.833-0.976 which meant that the tests were highly reliable and suitable for the study.

\section{- Program Content}

- Explanation.

The

researcher explained the ideal techniques to master the selected offensive skills of handball to the experimental group.

- Computers. A series of videos was displayed to the experimental group showing sample models of the selected handball skills.

- Handouts. A series of pictures were shown to the experimental group showing sample models of the selected handball skills.

- Modeling. The researcher, accompanied by a colleague, applied some techniques to show the skills needed to be mastered by students. Students who mastered the skills were also used as models for their colleagues.

- Time Allotted. The program consisted of 10 units and took 10 weeks to complete (see Appendices 6 and 7).

\section{- Procedures}

- Pre-test.

Pretest administrations to the control and experimental groups were done on February 2 and 3, 2015.

- Actual Administration. The proposed mastery-based program and the traditional one were administered to the experimental and control groups respectively. The proposed mastery-based program started on February 23, 2015 and ended on May 4, 2015 while the traditional program started on February 24, 2015 and ended on May 5, 2015.

- Post-test. Posttest administrations to the control and experimental groups were done on May 6 and 5, 2015, respectively.

\section{Findings}

- Statistical Tests

To answer the study questions and verify its 
hypotheses descriptive statistics tests were used; namely means, medians, standard deviations, t-test, correlation coefficients and improvement percentages.

- Results \& Discussion

- Hypothesis 1. There are significance statistical differences between the mean scores of the pre-and postmeasurements for the experimental group in the performance level of some offensive skills in the handball in favor of the post measurement.

As shown in the following table, it can be concluded that Hypothesis 1 is accepted.

\section{Table (2)}

Mean scores of the experimental groups on the pre- and postmeasurements $\mathbf{N}=\mathbf{3 0}$

\begin{tabular}{|c|c|c|c|c|c|c|c|c|}
\hline \multirow{2}{*}{ Tests } & \multirow{2}{*}{$\begin{array}{l}\text { Measurement } \\
\text { Unit }\end{array}$} & \multicolumn{2}{|c|}{ Pre-test } & \multicolumn{2}{|c|}{ Post-test } & \multirow{2}{*}{ M } & \multirow{2}{*}{$\begin{array}{l}\text { T } \\
\text { Value }\end{array}$} & \multirow{2}{*}{$\begin{array}{l}\text { Improvement } \\
(\%)\end{array}$} \\
\hline & & $\mathbf{M}$ & SD & M & SD & & & \\
\hline $\begin{array}{c}\text { Pass } \\
\text { \&catching }\end{array}$ & score & 16.00 & 4.02 & 20.70 & 2.44 & 4.70 & $7.681 *$ & 29.38 \\
\hline Dribbling & seconds & 28.91 & 1.85 & 26.81 & 1.86 & $2.10-$ & $5.810^{*}$ & 7.26 \\
\hline $\begin{array}{c}\text { Standing } \\
\text { shot }\end{array}$ & score & 4.10 & 2.22 & 5.60 & 2.51 & 1.50 & $5.33^{*}$ & 36.59 \\
\hline Jump shot & score & 0.80 & 0.51 & 2.90 & 2.63 & 2.10 & $9.245^{*}$ & 262.5 \\
\hline
\end{tabular}

Notes. *Significant at $0.05=\underline{(2.048)}$

The results indicated in Table 2 that there are statistically significant differences between the preand post-measurement in the search variables for the benefit of the post-measurement. The researcher attributed this to the fact that the use of the learning strategy for masturbation led to an improvement in the skill level of the students in the handball. Abdul-Hamid Sharaf (2002) that the acquisition of different skill is done in more than one way in a well-planned system, using more than one sense of the body. (2:73). This finding is in line with the results of Mostafa Sami Emera (2014) (13), Joseph and Nancy (1999) (14), who found that using mastery learning methods positively affected their student's physical skills needed for sports.

- Hypothesis 2. There are significance statistical 
differences between the mean scores of the pre-and postmeasurements for the control group in the performance level of some offensive skills in the handball in favor of the post measurement.

As can be seen in the following table, it can be concluded that Hypothesis 2 is also accepted.

\section{Table (3)}

Mean scores of the control groups on the pre- and postmeasurements $\mathbf{N}=\mathbf{3 0}$

\begin{tabular}{c|c|c|c|c|c|c|c|c}
\hline \hline \multirow{2}{*}{ Tests } & \multirow{2}{*}{$\begin{array}{c}\text { Measurement } \\
\text { Unit }\end{array}$} & \multicolumn{2}{|c|}{ Pre-test } & \multicolumn{2}{|c|}{ Post-test } & M & $\begin{array}{c}\text { T } \\
\text { Value }\end{array}$ & $\begin{array}{c}\text { Improvement } \\
(\%)\end{array}$ \\
\cline { 3 - 7 } & M & SD & M & SD & & 22.41 \\
\hline \hline $\begin{array}{c}\text { Pass } \\
\text { \&catching }\end{array}$ & score & 20.70 & 2.44 & 17.92 & 3.21 & 2.78 & $3.552 *$ & 3.06 \\
\hline Dribbling & seconds & 26.81 & 1.86 & 27.54 & 1.44 & $0.73-$ & $3.979 *$ & 16.28 \\
\hline $\begin{array}{c}\text { Standing } \\
\text { shot }\end{array}$ & score & 5.60 & 2.51 & 5.00 & 2.91 & 0.60 & $4.289 *$ & 157.14 \\
\hline Jump shot & score & 2.90 & 2.63 & 1.80 & 3.09 & 1.10 & $3.033^{*}$ & 14 \\
\hline \hline
\end{tabular}

Notes. *Significant at $0.05=(\underline{2.048)}$

Table (7) illustrate the improvement of remote measurements of tribal measurements for control group students at the level of learning offensive skills (under consideration). The researcher explains this progress in the level of performance that the administrators of the educational process in the faculty rely on the verbal explanation and the performance of the practical model in their teaching, and thus return students in this way to learn a lot of motor skills in most other subjects. This is what Abdel-Karim (1994) showed in her study where she explained the role of traditional teaching methods in teaching students the physical skills needed for some sports. (3:90)

- Hypothesis 3. There are significance statistical differences between the mean scores of the two posts of the experimental and control group in the performance level of some offensive skills in the handball in favor of the experimental group.

As displayed in the following table, it can be concluded that Hypothesis 3 is accepted.

\section{Table (4)}


Mean scores of the control and experimental groups on the postmeasurements $\mathbf{N}=\mathbf{3 0}$

\begin{tabular}{l|l|l|l|l|l|l|l}
\hline \hline \multirow{2}{*}{ Tests } & \multirow{2}{*}{$\begin{array}{l}\text { Measurement } \\
\text { Unit }\end{array}$} & \multicolumn{2}{|l|}{$\begin{array}{l}\text { Exp. } \\
\text { Group }\end{array}$} & \multicolumn{3}{l|}{$\begin{array}{l}\text { Control } \\
\text { Group }\end{array}$} & \multirow{2}{*}{ M } \\
\cline { 3 - 7 } & & Value \\
\hline \hline $\begin{array}{l}\text { Pass } \\
\text { \&catching }\end{array}$ & score & 14.64 & 3.12 & 17.92 & 3.21 & 3.28 & $5.42^{*}$ \\
\hline Dribbling & seconds & 28.41 & 1.73 & 27.54 & 1.44 & $0.87-$ & $4.51^{*}$ \\
\hline $\begin{array}{l}\text { Standing } \\
\text { shot }\end{array}$ & score & 4.30 & 2.00 & 5.00 & 2.91 & 0.70 & $5.52^{*}$ \\
\hline Jump shot & score & 0.70 & 0.37 & 1.80 & 3.09 & 1.10 & $4.68^{*}$ \\
\hline \hline
\end{tabular}

Notes. $*$ Significant at $0.05=(\underline{2.048)}$

Table (4) shows the improvement of the distance measurements of the experimental group's students about the dimension measurements of the control group students in the level of learning the offensive skills in the handball (under study). The researcher attributed this to the reason that the learning program in the learning method of mastery was concerned with several aspects to improve the learning process and taking into consideration the individual differences between students, and providing sufficient time for learning so that the students' progress in learning according to the speed of their own response, and also the presence of visual effects associated with images or models. All this has contributed greatly to increasing the motivation to learn, which has led students to feel satisfied with their skillful performance, and thus to enhance their self-confidence and ability to challenge the difficult new skills and try to perform them successfully.

These results are consistent with the study of Emera (2014) (13), Khalaf (2013) (5) Abdul Aziz (2012) (4), Abdullah (2012) (9), Abdul Fattah (2009) (7) that the learning method of masturbation achieved better results than the traditional method of learning offensive handball skills. 


\section{Conclusions}

\&

Recommendations

In light of the study results, it can be concluded that:

1. Using the "mastery learning" as a teaching method positively affects students' learning of the offensive handball skills (the experimental group).

2. Using the traditional learning method positively affects students' learning of the offensive handball skills (the control group).

3. The "mastery learning" as a teaching method has a better impact on students' learning of the offensive handball skills more than the traditional learning method does.

In so doing, it can be recommended that:

1. Use "mastery learning" methods to teach handball lectures at the Physical Education Department of Umm El-Qura University.

2. Use" mastery learning" as a teaching methods and its effect on performance level on other practical courses in the Physical Education Department be further studied and examined.
3. Organizing training sessions and workshops for teachers on "mastery learning" method and their cognitive and effective impact.

4. Organizing training sessions and workshops on recently teaching methods as the student reacts positively.

\section{References}

\section{Arabic References}

1- Abd Ali Mohamed Hassan (1995): The School

Curriculum, First Edition. Bahrain: University of Bahrain

\section{2- Abdel-Hamid Sharaf} (2002): Physical and motor education for children with disabilities and disability, the book center for publishing, Cairo

3- Afaf Abdel-Karim (1994): Teaching for learning in physical education and sport, Knowledge facility, Alexandria

4- Ahmed Mohamed Abdel Aziz Mohamed (2012): The Effectiveness of the Learning Method for Mastering Caricatures in Learning Some Handball Skills for Preparatory Students, Scientific Journal of Physical Education and Sport, Egypt

5- Ali Mohamed Khalaf (2013): Effect of using the method of technical learning in 
the accuracy of the performance of some basic skills of football, Journal of Physical Education Sciences, Volume VI, Baghdad

6- Hassan Sayed Hassan Shehata (2008): Modern Teaching and Learning Strategies and Arab Mind Industry Egyptian Lebanese Library for Publishing

7- Hossam El-Din Nabih Abdel-Fattah (2009): Effect of learning method to master the development of basic skills of goalkeeper in handball Assiut Magazine for Sports Science and Arts - Egypt

8- Ismail Mohamed Sadiq (2001): Methods of Teaching Mathematics - Theories and Applications, Dar Al-Fikr AlArabi, Cairo

9- Mohamed Ahmed Abdullah (2012): Effect of the use of the learning strategy to master the level of performance of the strike skill projected in squash Scientific journal of physical education and sports, Egypt
10- Mohammed Fakhri Mikdadi (1988): Learning to Mastery, Teacher's Message, Ministry of Education, Jordan, Second Issue, Volume 29, 11-Mohamed Hassan Allawi, Kamal Darwish, Emad Abbas (2003): Psychological preparation in handball theories - Cairo Applications Book Center for Publishing 12- Mohamed Tawfiq Al Waili (2004): Handball (Education - Training - Tactic) Cairo

13- Mostafa Sami Emera (2014): The Effect of Using Learning to Achieve the Level of Performance in the Butterfly and Motion Satisfaction of the Students of the Faculty of Physical Education Sadat University - The Scientific Journal of Physical Education and Sport - Egypt

\section{Foreign References}

14- Joseph G. R. Martinez \& Nancy C. Martinez (1999): Teacher Effectiveness and learning for Mastery, Journal of Education Research, May, Vol.92, issue5 